\title{
The Role of Tacit Routines in Coordinating Activity
}

\author{
Scott Rick \\ Department of Social \& Decision Sciences \\ Carnegie Mellon University \\ Roberto A. Weber \\ Department of Social \& Decision Sciences \\ Carnegie Mellon University \\ Colin F. Camerer \\ Division of Humanities \& Social Sciences \\ California Institute of Technology
}

May 22, 2006*

\begin{abstract}
:
We explore the influence of tacit routines in obtaining coordination. Our experiment uses simple laboratory "firms," in which we interfere with one kind of firm's ability to develop tacit routines. Thus, our firms vary in the degree to which they rely on this kind of knowledge - instead of other, explicit, mechanisms - for obtaining coordination. We find that interfering with the development of tacit routines harms firms' ability to coordinate. We then explore the extent to which firms are able to transfer their ability to coordinate activity, either to a new domain or to new members. Our results indicate that tacit routines transfer more easily than other mechanisms to a new, but closely related, domain. However, routine-based firms perform slightly worse in their ability to incorporate new members.
\end{abstract}

\footnotetext{
* This research was supported by NSF grant SES-0095570 to Camerer and Weber and an NSF Graduate Research Fellowship to Rick. We thank participants at the 2003 ESA conference in Pittsburgh, the 2003 SITE conference in Stanford, the 2003 NBER conference on organizational economics in Boston, the 2004 BDRM meetings in Durham, the 2004 Strategy Research Forum in Toronto, and the 2004 ESA conference in Amsterdam, as well as seminar participants at Carnegie Mellon, UCLA, Caltech, and Duke for helpful comments and suggestions.
} 
Organizational actors often confront tasks in which coordinated action is important (March and Simon 1958, Thompson 1967, Camerer and Knez 1997). Perhaps the simplest such tasks are those in which the actions of employees need to correspond to the directives of managers. For instance, a manager may receive private information about an exogenous variable (characteristics of products demanded by consumers) and issue a directive on how employees should act (which characteristics to emphasize in development, marketing, or sales). Coordination and efficiency are obtained when employees act in a manner consistent with each other's actions, the manager's intentions, and the information about the exogenous variable.

While the abstract problem of matching employees' actions with a manager's directives may seem trivial, it is often quite difficult to obtain efficient coordination in practice, even in simple tasks with small numbers of possible actions and individuals (Mehta et al. 1994; Van Huyck et al. 1990) and even when there is communication from a manager about what action to take (Weber et al. 2001). Thus, understanding how organizational actors coordinate their behavior is important for understanding the mechanisms underlying organizational efficiency.

While communication can play a role in aiding coordination (Marschak and Radner 1972, Arrow 1974, Daft and Lengel 1986, Blume and Ortmann 2005), the knowledge shared by members of a group or firm can also be critically important and may influence the need for communication. When members have little shared knowledge, a large amount of communication is required to coordinate activity, but less communication is needed when members share a large body of knowledge (Arrow 1974, Cremer 1993). Thus, shared knowledge - for instance, of what a firm has done in the past or of "programmed" practices for facilitating coordination - may be a substitute for communication in achieving coordination (Argote 1982, Weber 2006; see also, Schelling 1960). 
Given the importance of shared knowledge in facilitating coordination, it is important to note that not all knowledge in organizations is the same. Organizational scholars note that knowledge varies in the extent to which it is explicit or codifiable, and that this also applies to knowledge shared among firm members (Cohen and Bacdayan 1994, Nonaka 1991, 1994, Winter 1987, Zander and Kogut 1995, Lam 2000). ${ }^{1}$ In particular, several scholars divide knowledge jointly held by firm members into explicit (codifiable) shared knowledge and implicit shared knowledge, frequently referred to as tacit routines.

In this paper, we explore the use of tacit routines - in contrast to other mechanisms such as communication and explicit shared knowledge - in solving coordination problems. To do so, we create simple laboratory "firms," whose only function is to solve coordination problems requiring correspondence between a manager's private information and the actions of several employees, and limit one kind of firm's ability to develop tacit routines. Thus, we develop firms that differ in the extent to which they rely on tacit routines ("routine-intensive" firms), versus other mechanisms ("routine-restricted" firms), for coordination. We explore how these firms differ in their ability to solve simple coordination problems, and also in the extent to which they are able to transfer such ability to new domains and individuals.

\section{Communication, Explicit Knowledge and Tacit Routines}

We explore the use of shared knowledge in coordinating activity, noting that there are two kinds of shared knowledge that firm members develop through repeated interaction. We focus on the distinction between explicit, codifiable, or declarative knowledge (henceforth “explicit knowledge") and tacit, routine-based, or procedural knowledge (henceforth "tacit

\footnotetext{
${ }^{1}$ This general distinction has also been noted by philosophers (Polanyi 1966), psychologists (Anderson 1982, Singley and Anderson 1989), organizational researchers (von Hippel 1988, Cohen 1991, Walsh and Ungson 1991, Kogut and Zander 1992) and economists (Hayek 1945, Nelson 1982).
} 
routines"). This distinction - noted previously by organizational and economic scholars (e.g., Winter 1987, Nonaka 1994, Zander and Kogut 1995) - is important for understanding sources of organizational efficiency, particularly when coordination among individuals is important (Nonaka 1991, Cohen and Bacdayan 1994). Moreover, we focus only on the kind of knowledge that is shared among firm members, and is therefore useful for solving coordination problems. ${ }^{2}$

To be precise, in this paper explicit knowledge corresponds to the codifiable body of publicly held knowledge among firm members that assists in coordination. For instance, employees in a firm may receive guidelines (e.g., manuals, training, or explicit instruction) on how to respond to managers' directives, and employees can refer to this body of explicit, shared knowledge whenever they need to infer management's desired action. As another example, a manager and employee may meet regularly to reach explicit agreement about which activities the employee will perform following different directives from the manager. A key feature of this kind of knowledge is that it is closely related to the use of communication. For instance, both communication and the use of explicit shared knowledge solve coordination problems through the establishment of explicit agreement regarding behavior. Moreover, establishing the kinds of guidelines or explicit agreement discussed above usually requires communication between people in the firm, and the more communication in which they engage, the more likely such explicit knowledge is to develop (Nonaka 1991).

In our framework, tacit routines refer to the implicit knowledge or unstated shared agreement between firm members regarding how to take actions in a manner likely to produce successful coordination. This kind of knowledge corresponds to jointly held perspectives, procedures and patterns of behavior that arise through repeated interaction, but which are

\footnotetext{
${ }^{2}$ Lam (2000) provides a classification of knowledge types that is useful for our purposes. She distinguishes knowledge on two dimensions: epistemological (explicit vs. tacit) and ontological (individual vs. collective). We focus on the distinction between explicit collective (shared) knowledge and tacit collective (shared) knowledge.
} 
independent of explicit communication or codification. For instance, an employee may learn which types of activities a manager prioritizes, by having worked together for a long time and without any explicit discussion of the manager's tendencies. Similarly, an employee may develop an understanding of the particular order or manner in which a manager likes to receive or dispense different kinds of information, without either ever explicitly discussing this. While this kind of shared knowledge may not require communication to develop, as explicit knowledge does - and firm members may not even possess awareness of tacit routines - it still requires a shared history of repeated performance of near identical activities (Gersick and Hackman 1990, Nonaka 1994).

In solving coordination problems, both kinds of knowledge are important, but they are also substitutes for the use of communication. ${ }^{3}$ Firm members can coordinate activity between each other with very little shared knowledge, but this likely requires a great deal of communication. On the other hand, if firm members possess a great deal of shared knowledge of either kind - then significantly less communication is required to achieve coordination.

\section{Coordination and Tacit Routines}

In this paper, we explore the influence of tacit routines on coordination, using simple laboratory firms. We do so by interfering with one kind of firm's ability to develop this kind of shared knowledge. As a result, these firms must rely more heavily on communication and explicit knowledge. In the appendix, we provide a formal theoretical illustration of how limiting a firm's ability to develop tacit routines, in a production task similar to that in our experiments, can produce greater reliance on communication and a larger body of shared explicit knowledge.

\footnotetext{
${ }^{3}$ Arrow (1974), Nelson and Winter (1982), Cremer (1993), Wernerfelt (2003), and Cremer et al. (2005) also discuss the efficiency-enhancing nature of shared knowledge in facilitating coordination, and how this relates to the use of communication.
} 
We motivate our work with three simple hypotheses.

First, we predict that interfering with firms' ability to develop tacit routines will harm their ability to solve coordination problems and will force them to rely more heavily on communication and explicit knowledge. That is, in our task - where the only thing firms do is coordinate activity - we predict routine-restricted firms will produce lower earnings and require more communication than routine-intensive firms.

We then explore how the induced difference influences firms' ability to cope with two kinds of change. More precisely, we explore whether routine-intensive or routine-restricted firms are better at dealing with situations in which it is necessary to transfer knowledge in order to continue to successfully solve coordination problems.

The first kind of change corresponds to the firm entering a new domain, where the basic features of the coordination problem remain the same, but the domain over which such coordination must occur changes. ${ }^{4}$ In this case, the firm must perform the same task as before (coordinating the manager's exogenous private information with employees' actions), but in a new context. Based on previous research we anticipate that tacit routines will transfer to the new context, due to high similarity between what the firm does in both cases, but that domain-specific explicit coordination mechanisms (i.e., shared explicit knowledge) will not (Berry and Broadbent 1987, Gersick and Hackman 1990, Cohen and Bacdayan 1994, Darr and Kurtzberg 2000). Thus, we predict routine-intensive firms will perform better than routine-restricted firms in transferring knowledge to a new closely related domain.

In the other kind of change, we introduce a new employee. This corresponds to a situation in which a firm grows by adding new individuals, thus requiring transfer of knowledge

\footnotetext{
${ }^{4}$ For instance, a firm may enter a new geographical or consumer market for its product (or introduce a new closely related product). Alternatively, a service firm might regularly deal with new clients, in which case the basic features of what the firm does remain unchanged, but the precise domain over which activity must be coordinated differs.
} 
to the new member. In this case, we anticipate that transfer will be nearly impossible for tacit routines, which are difficult to transfer to new individuals if not accompanied by explicit information (Weber 2006). However, we anticipate new employees will find it easier to access the explicit coordination mechanisms, relied on more heavily by routine-restricted firms, which are codifiable and therefore easier to transmit without shared experience (Nanaka 1991, 1994, Grant 1996, Argote and Ingram 2000, Lam 2000). Thus, we predict new employee performance to be better in routine-restricted firms than in routine-intensive firms.

\section{Coordination and Tacit Routines in Laboratory Firms}

Our experiment utilizes laboratory "firms" that perform a very simple task: a manager must convey privately observed information to several employees so that they can act in a manner coordinated with each other and with the manager's private information. More precisely, groups of participants in our experiment perform the picture-naming task introduced by Weber and Camerer (2003) to examine how firms develop shared knowledge useful for solving coordination problems.

In the laboratory task, a group of participants is presented with a set of pictures that they must jointly identify (cf. Clark and Wilkes-Gibbs 1986, Schober and Clark 1989). Specifically, a manager with access to private information (the appropriate pictures) must convey this information to employees (by describing the pictures) and the employees must respond with the action desired by the manager (selecting the appropriate pictures). To perform this task with as few mistakes as possible, the firm can rely on a combination of communication and shared knowledge. However, since communication is costly - it takes time - the firm can perform 
better by developing shared knowledge (both explicit knowledge and tacit routines) and substituting away from the use of communication. ${ }^{5}$

The only jointly held explicit knowledge with which members begin the task is common knowledge of the English language and perhaps a few other jointly held declarative facts. ${ }^{6}$ However, through repeated communication they develop explicit knowledge, in the form of a precise code or jointly agreed upon set of terms that uniquely identify each of the pictures. As the task continues, they develop an improved body of explicit knowledge matching words or phrases to pictures. ${ }^{7}$

Similarly, firm members begin the task with a very limited set of jointly held tacit routines, such as basic implicit communication procedures (like allowing the manager to speak first). ${ }^{8}$ However, through repeated interaction firm members develop tacit routines useful for identifying the pictures. For instance, employees may develop tacit understanding that the manager tends to refer to pictures primarily based on one kind of feature or begin with a particular area on the pictures. Managers and employees may also develop certain tacit communication routines to aid their ability to coordinate. ${ }^{9}$

\footnotetext{
${ }^{5}$ Weber and Camerer (2003) utilize this shared knowledge as a metaphor for organizational culture. More precisely, an experiment demonstrates that two groups independently developing shared knowledge (both tacit and explicit) over the same sets of pictures have a difficult time integrating their unique knowledge when merged. The fact that this difficulty is unanticipated and that individuals blame members of the other group for such difficulties parallels similarities between the integration of two groups with different shared knowledge in the laboratory and the integration of distinct organizational cultures following a merger.

${ }^{6}$ For instance, one of the firms in Weber and Camerer (2003) consisted of two people who both had taken a class from the same professor, and they remembered his name. This initial shared explicit knowledge proved valuable in performing the task - they ended up referring to one of the pictures by this professor's name (because they jointly recognized a resemblance between someone in the picture and the professor).

${ }^{7}$ In the Weber and Camerer experiments this knowledge was clearly explicit since participants asked at the end of the experiment to write down the list of codes were able to do so without difficulty or much disagreement within firms (beyond minor semantics).

${ }^{8}$ An example of such implicit communication routines, held widely among members of a population, can be seen in differences between how time is generally described in communication by English (vertically) and Mandarin (horizontally) speakers (Boroditsky 2001).

${ }^{9}$ For example, in the Weber and Camerer experiments, firms developed tacit conventions such as focusing on what people were wearing or how many people were in each picture. Also in those experiments, firms differed substantially in how the employees affirmed that they had understood the manager's directive - in some cases
} 
Thus, while firm members begin their interaction with limited amounts of either kind of shared knowledge, and therefore initially rely heavily on communication, repeatedly performing the task increases the amount of both kinds of jointly held knowledge. As a result, managers and employees improve their ability to coordinate while minimizing the need for communication. ${ }^{10}$

Since both kinds of knowledge are helpful in solving coordination problems, it is useful to understand how they each impact firms' ability to coordinate. However, separating the impact of the two kinds of knowledge on performance is difficult. Most firms develop simultaneously both explicit knowledge and tacit routines. Therefore, it is hard to determine which is primarily responsible for improving performance, and it is also hard to determine the effects of a firm's reliance on one kind of knowledge more than the other. In this paper, we do so by limiting the ability of one kind of firm to develop tacit routines.

The development of tacit routines depends on repeated near-identical interaction between organizational members. That is, repeated interaction between individuals, in the same roles, is likely to lead to the development of such routines (Gersick and Hackman 1990, Cohen and Bacdayan 1994). Therefore, in our experiment we simply vary whether firm members' roles remain fixed or change from period to period. Specifically, we vary whether the role of manager remains fixed on one participant or rotates among each firm member. ${ }^{11}$

In firms with fixed roles (routine-intensive firms) members should be easily able to develop tacit routines facilitating the performance of the task from one period to the next.

silence indicated agreement, in others an "uh huh" or "got it" was required. In both cases these differences often led to unanticipated conflict in "merged" firms.

${ }^{10}$ In the Weber and Camerer experiments firms took an average of 249 seconds (of communication) to complete the first period of the task and 48 seconds to complete the $20^{\text {th }}$ period.

${ }^{11}$ Our experiments are therefore similar to an earlier line of research that investigated how the structure of an organization's "communication net" affects its ability to perform routines (Bavelas 1950, Bavelas and Barrett 1951, Carzo, Jr. and Yanouzas 1969, Christie et al. 1956, Guetzkow and Simon 1955, Leavitt 1951, 1962, Shaw 1954).

However, unlike this earlier research, varying whether the role of manager remains fixed or rotates in our experiment produces no change in how the laboratory task is performed in any period - one participant always performs the task as manager while the others serve as employees. 
Conversely, we interfere with the ability of members of firms with rotating roles (routinerestricted firms) to develop such routines by forcing them to repeatedly change roles. As a result, we force such firms to rely more heavily on explicit coordination mechanisms (communication and shared explicit knowledge). ${ }^{12}$ Since firms are otherwise identical, this distinction allows us to explore the possible influence of the two kinds of knowledge on firm performance and the transfer of their knowledge, either to a new domain or a new employee.

Organizational scholars have noted the importance associated with firm knowledge and the transfer of such knowledge as a source of competitive advantage (Nelson and Winter 1982, Grant 1996, Argote et al. 2000). However, scholars also note that tacit routines, by their very nature, are difficult to observe empirically (Hall 1993, Spender and Grant 1996). Our work, using controlled laboratory experiments in which we can influence the kind of knowledge possessed by firms, explores precisely how different kinds of knowledge can yield advantage in coordinating activity and in transferring such ability in situations regularly faced by firms. ${ }^{13}$

\section{Experimental design and procedures}

Our experiment consisted of a $2 \times 2$ design that varied the type of knowledge developed by the firm (routine-intensive vs. routine-restricted) and the type of change the firm underwent after

\footnotetext{
${ }^{12}$ The simple model in the appendix illustrates how a firm with weakened ability to develop tacit routines, as in our experiment, will compensate by communicating more and developing a greater stock of explicit agreement.

${ }^{13}$ This also raises an important caveat to our research: what can we learn about firms from laboratory experiments? We acknowledge that our "firms" are very simple, and only do one thing: coordinate activity between a manager and several employees. However, using simple laboratory firms, only engaged in solving coordination problems, allows us to address precisely how such coordination is influenced by firms' knowledge, while controlling for other factors usually present outside the laboratory. Moreover, by using laboratory experiments, we can directly influence the development of firms' knowledge, something impossible to do in naturally-occurring contexts. Thus, the simplicity of the laboratory makes it an ideal environment in which to generate data on laboratory "firms" to complement the study of real-world firms. Of course, using the laboratory to understand processes in real-world firms requires sacrificing important features present in such firms (see Weick 1969).
} 
the first 20 periods (new domain vs. new employee). We first describe the general procedures utilized over the first 20 periods and then describe treatment differences.

\section{General procedures for periods 1-20}

In every session, four (new domain treatment) or five (new employee treatment) participants arrived at the experiment and were randomly-assigned participant numbers (1-4 or 15). In new employee sessions, the participant who received the number 5 was asked to leave, return in 30 minutes, and told that he or she would receive $\$ 5$ for returning on time.

The (remaining) four participants received instructions on performing the codedevelopment task. ${ }^{14}$ They also each received the same eight numbered pictures on four sheets of paper. The pictures were of the same kinds of office environments as those used in Weber and Camerer (2003). Participants were told that in each period there would be a manager and three employees. The manager would see numbers corresponding to four of the pictures and would have to try to get the employees to reproduce the ordered list of numbers while only referring to the content of the corresponding pictures.

The four participants were seated at tables facing in opposite directions and each received a stopwatch. When a period started, all employees started their stopwatches (the experimenter also kept time). At that point, participants were free to talk back and forth. Once a particular employee wrote down four numbers, he or she stopped the watch and recorded the time. ${ }^{15}$ Once all the employees finished, the experimenter read the correct numbers aloud, and participants noted whether the number they had placed in each position was correct, recording the number of

\footnotetext{
${ }^{14}$ Instructions can be found online at www.andrew.cmu.edu/ $\sim$ srick.

${ }^{15}$ Once one minute elapsed, the period ended whether or not participants completed identifying all four pictures. If an employee did not identify all four pictures in one minute, the employee earned nothing in that period.
} 
mistakes. ${ }^{16}$ The payoffs to each employee for completing the task in a period were $\$ 0.60$ minus $\$ 0.01$ for each elapsed second, and a $\$ 0.10$ per mistake penalty. The manager received the average of the three employees' earnings.

\section{Firm knowledge treatments}

In one half of these sessions (routine-restricted firms) the role of manager changed every period according to participant numbers (participant 1 was manager in periods $1,5,9$, etc.). In the remaining sessions (routine-intensive firms) participant 1 was always manager.

In all sessions, the four participants completed 20 periods of this task, which took about 25 minutes. Following period 20, the experimenter read aloud a new set of instructions, which differed by the second treatment.

\section{New domain treatment}

After period 20, participants received a new set of eight pictures, also depicting office environments. Participants were told that they would perform another 15 periods of the task in the same manner as before, but with the new set of pictures. Participants then proceeded as before for 15 periods. The role of manager continued to be either fixed or rotating.

New employee treatment

We added to the firm a fifth employee for periods 21 through 35 . Recall that in each session of the new employee treatment, five participants initially arrived at the experiment. The

\footnotetext{
${ }^{16}$ The experimenter stood between the participants at all times, from a position where he could easily see if a participant was writing when he or she was not supposed to or changing previously written numbers. This situation did not arise. The experimenter also checked participants' record sheets to determine the manager's earnings and to make sure that recording was accurate and that participants knew how to calculate earnings.
} 
participant who drew the number 5 was asked to leave and return in 30 minutes. Upon returning to the experiment, participant 5 was asked to wait outside for a few minutes and received a copy of the instructions. ${ }^{17}$ Starting with period 21, participant 5 was always in the role of employee. In routine-restricted firms, the role of manager continued to rotate among participants 1 through 4, while in routine-intensive firms, the role of manager remained with participant 1.

\section{Participants}

Participants were Carnegie Mellon and University of Pittsburgh undergraduate and graduate students who had not previously participated in any other experiment involving this paradigm. Participants were recruited from an e-mail list of interested students. The e-mail announcement requested that only participants fluent in spoken English sign up.

We conducted a total of 40 sessions using 184 participants. Table 1 presents the number of sessions and participants by treatment.

\section{Results}

In presenting our results, we proceed as follows. First, we analyze differences in the first 20 periods in the relative ability of routine-intensive and routine-restricted firms to solve the repeated coordination problem. We then explore the degree to which this ability transfers either to the new domain or to the new employee.

\section{Periods 1-20}

Figure 1 presents the average earnings, by period and by type of firm, in the first 20 periods. As we expected, interfering with one kind of firm's ability to develop tacit routines

\footnotetext{
${ }^{17}$ Before proceeding to period 21, participant 5 had an opportunity to ask questions about the task.
} 
interferes with those firms' ability to solve the coordination problem. ${ }^{18}$ In all periods after the first, earnings are higher in routine-intensive firms that in routine-restricted firms. ${ }^{19}$

The advantage obtained by routine-intensive firms can also be seen in Table 2, which presents the results of regressions, using random firm effects, of earnings on period (using the natural logarithm of period to account for decreased improvement in performance over time) and treatment variables. ${ }^{20}$ The first regression examines the effect of limiting the development of tacit routines on firm performance. Of primary interest is the binary variable Routine-Intensive, which is equal to one for routine-intensive firms and zero for routine-restricted firms. As the coefficient on this variable indicates, routine-intensive firms enjoyed a significant advantage in performance over the first 20 periods of the experiment. Thus, limiting the development of tacit routines - by limiting the degree to which roles in performing the task are identical across periods - clearly hinders performance.

\section{New domain}

Figure 2 presents the average earnings of firms in the new domain treatment, for the 15 periods in which they performed the task with new pictures (periods 21-35). Pooling across both kinds of firms, we find evidence of transfer of coordination ability to the new domain: in Figure 1 firms start off very close to $\$ 0.00$, while in Figure 2 they start off very close to $\$ 0.30$.

\footnotetext{
${ }^{18}$ The results in the model in the appendix refer to both earnings and communication - the relationship between the two is always predicted to be negative, as firms with greater stocks of shared agreement require less communication. We find this to strongly be the case. The correlation, across all periods and firms between time (which measures the amount of communication) and firm earnings is -0.97 . Of course, in our experiment, the payoffs are such that communication and earnings are very likely to be negatively correlated, as is the case in the model. For brevity, we limit our analysis of the results to firm earnings, but note that an analysis of the amount of communication would produce results that are substantively identical, but with opposite signs, thus providing support for our predictions.

${ }^{19}$ The lack of a difference in the first period suggests that managers are "myopic" (see model in the appendix), in the sense that routine-restricted firm managers are unaware of the greater potential benefits to them - relative to routineintensive firms - of using more communication in the first period as an investment in the development of explicit agreement.

${ }^{20}$ The results are substantively unchanged if we omit the random-effects and instead allow clustering of standard errors by firm.
} 
The figure also reveals that the advantage obtained by routine-intensive firms in periods 1-20 transfers to the new domain. A comparison of the average earnings over the first four periods - one managerial "cycle" in the routine-restricted firms - reveals significantly higher earnings for routine-intensive firms than for routine-restricted ones (routine-intensive: $\$ 0.40$; routine-restricted: $\left.\$ 0.30 ; \mathrm{t}_{14}=2.97, \mathrm{p}=0.01\right){ }^{21}$

The greater ability of routine-intensive firms to coordinate in the new domain can also be seen in Table 2, in the second and third regressions. In both regressions - which vary only in the inclusion of period 20 firm earnings as a control in the latter - the coefficient for routineintensive firms is positive and significant, indicating that these firms maintain their advantage in the new domain.

A more direct test of whether greater transfer occurs in routine-intensive firms can be seen in Table 3. This table reports regressions of average earnings in periods 21 through 24 (using the firm as the unit of observation), controlling for that firm's average earnings in periods 1 through 4 . The first regression demonstrates that how a firm performs in the new domain is only slightly related to how it performed initially in the previous domain (the coefficient on average period 1 through 4 earnings is marginally significant $p=0.11$ ), but that there is significant transfer to the new domain (the coefficient on the constant term is positive). That is, in dealing with the new set of pictures, firms initially perform much better than they did at the beginning of the experiment (with the first set of pictures), indicating that they are able to transfer some of the shared knowledge developed over the first 20 periods. The second regression shows that this transfer is significantly larger for the routine-intensive firms.

New employee

${ }^{21}$ All p-values are based on two-tailed tests. 
Figure 3 presents the average earnings, across periods 21 through 35, for the participant added to the firm in the new employee sessions. Comparing Figures 1 and 3, we see only very slight evidence of transfer to the new employee. While earnings at the beginning of the experiment (Figure 1) began close to $\$ 0.00$, the average earnings for the new employee begin close to $\$ 0.04$. However, the increase in earnings across time (i.e., the slope of the lines) appears to be larger in Figure 3 than in Figure 1 - e.g., by period 25, new employees average earnings are around $\$ 0.38$, while they are only about $\$ 0.24$ by period 5 in Figure 1 - providing some evidence of transfer of coordination ability to the new employee.

The figure reveals only slightly better initial performance for the new employee in the routine-restricted firms, as we had expected. While average earnings in the first four periods (21-24) are higher for routine-restricted firms (\$0.23) than for routine-intensive firms $(\$ 0.19)$, this difference does not reach standard significance levels $\left(\mathrm{t}_{22}=1.53, \mathrm{p}=0.14\right)$. Looking at Table 2, we similarly see only slightly - and insignificantly - better performance by the new employee in the routine-restricted firms than in the routine-intensive ones. ${ }^{22}$

In Table 3, we see that firms are able to transfer some of their coordination ability to the new employee (in the first four periods). That is, the coefficient for the constant is positive and statistically significant when we pool the two kinds of firms (third regression). However, this transfer is only slightly smaller for routine-intensive firms, and the coefficient is not significantly different from zero $(\mathrm{p}=0.16)$.

\section{Conclusion}

\footnotetext{
${ }^{22}$ We can alternatively assess new employees' relative performance by computing the ratio of their earnings to the average earnings of the original employees in their firm. The ratio in periods 21-24 is greater in routine-restricted firms (0.59) than in routine-intensive firms (0.44), though not significantly so $\left(\mathrm{t}_{22}=1.66, \mathrm{p}=0.11\right)$. However, the ratio in periods $21-35$ does differ significantly between routine-restricted and routine-intensive firms $(0.87$ vs. 0.74 ; $\left.\mathrm{t}_{22}=1.95, \mathrm{p}<0.07\right)$.
} 
This paper uses experiments on simple laboratory firms to understand the role of tacit routines in coordinating organizational activity, relative to other explicit coordination mechanisms such as communication and shared explicit agreement. We find that interfering with the development of tacit routines harms firms' ability to solve simple coordination problems. Specifically, routine-restricted firms, whose ability to develop tacit routines we interfered with, produced lower earnings and required more communication to complete the picture-naming task than did routine-intensive firms, who suffered no such interference.

We also explore the extent to which firms are able to transfer their ability to coordinate activity, either to a new domain or to a new member. Our results indicate that tacit routines transfer more easily than explicit knowledge to a new, but closely related, domain. However, routine-intensive firms perform slightly worse in their ability to incorporate new members, likely because tacit routines are less accessible to outsiders than is knowledge that can be explicitly communicated.

Naturally, the ideal setting for such work is real-world firms, where external validity is not an issue. However, the very nature of tacit routines makes them difficult to observe in the real world (Hall 1993, Spender and Grant 1996). In the laboratory, by contrast, we can exogenously vary the extent to which tacit routines are utilized by different firms, a task that would prove impossible among real-world firms. Nevertheless, it is important to note that our work should serve as a complement for the study of the role of tacit routines in coordination in real-world firms.

\section{References}

Anderson, J. R. 1982. Acquisition of cognitive skill. Psych. Rev. 89(4) 369-403 
Argote, L. 1982. Input uncertainty and organizational coordination in hospital emergency units. Admin. Sci. Quart. 27 420-434.

Argote, L., P. Ingram. 2000. Knowledge transfer: A basis for competitive advantage in firms. Organ. Behavior Human Decision Processes 82(1) 150-169.

Argote, L., P. Ingram, L. Levine, R. Moreland. 2000. Knowledge transfer in organizations: Learning from the experience of others. Organ. Behavior Human Decision Processes 82(1) $1-8$.

Arrow, K. A. 1974. The Limits of Organization. W.W. Norton \& Company, New York.

Bavelas, A. 1950. Communication patterns in task-oriented groups. J. Acoustical Society of America 22(6) 723-730.

Bavelas, A., M. Barrett. 1951. An experimental approach to organizational communication. Personnel 27 386-397.

Berry, D. C., D. E. Broadbent. 1987. The combination of explicit and implicit learning processes in task control. Psych. Research 49 7-15.

Blume, A., A. Ortmann. In press. The effects of costless pre-play communication: Experimental evidence from games with pareto-ranked equilibria. J. Econom. Theory.

Boroditsky, L. 2001. Does language shape thought? English and Mandarin speakers' conceptions of time. Cognitive Psych. 43(1) 1-22.

Camerer, C. F., M. Knez. 1997. Coordination in organizations: A game-theoretic perspective. Z. Shapira, ed. Organizational Decision Making. Cambridge University Press, Cambridge.

Carzo, Jr., R., J. N. Yanouzas. 1969. Effects of flat and tail organization structure. Admin. Sci. Quart. 14 178-191. 
Christie, L., R. Luce, J. Macy. 1956. Information handling in organized groups. J. F. McCloskey, J. M. Coppinger, eds. Operations Research for Management. Johns Hopkins Press, Baltimore.

Clark, H. H., D. Wilkes-Gibbs. 1986. Referring as a collaborative process. Cognition 22(1) 1-39.

Cohen, M. D. 1991. Individual learning and organizational routine: Emerging connections. Organ. Sci. 2(1) 135-139.

Cohen, M. D., P. Bacdayan. 1994. Organizational routines are stored as procedural memory: Evidence from a laboratory study. Organ. Sci. 5(4) 554-568.

Cremer, J. 1993. Corporate culture and shared knowledge. Indust. Corporate Change 2(3) 351386.

Cremer, J., L. Garicano, A. Prat. 2005. Codes in organizations. Working paper, Université de Toulouse, France.

Daft, R. L., R. H. Lengel. 1986. Organizational information requirements, media richness and structural design. Management Sci. 32(5) 554-571.

Darr, E. D., T. R. Kurtzberg. 2000. An investigation of partner similarity dimension on knowledge transfer. Organ. Behavior Human Decision Processes 82(2) 194-216.

Gersick, C. J., R. J. Hackman. 1990. Habitual routines in task-performing groups. Organ. Behavior Human Decision Processes 47(1) 65-97.

Grant, R. M. 1996. Toward a knowledge-based theory of the firm. Strategic Management J. 17 109-122.

Guetzkow, H., H. A. Simon. 1955. The impact of certain communication nets upon organization and performance in task-oriented groups. Management Sci. 1 233-250. 
Hall, R. 1993. A framework for linking intangible resources and capabilities to sustainable competitive advantage. Strategic Management J. 14(8) 607-618.

Hayek, F. A. 1945. The use of knowledge in society. Amer. Econom. Rev. 35(4) 519-530.

Kogut, B., U. Zander. 1992. Knowledge of the firm, combinative capabilities and the replication of technology. Organ. Sci. 3(3) 383-397

Lam, A. 2000. Tacit knowledge, organizational learning and societal institutions: An integrated framework. Organ. Studies 21(3) 487-513.

Leavitt, H. J. 1951. Some effects of certain communication patterns on group performance. $J$. Abnormal and Social Psych. 46(1) 38-50.

_. 1962. Unhuman organizations. Harvard Bus. Rev. 40(4) 90-98.

March, J. G., H. A. Simon. 1958. Organizations. John Wiley \& Sons, New York.

Marschak, J., R. Radner. 1972. Economic Theory of Teams. Yale University Press, New Haven.

Mehta, J., C. Starmer, R. Sugden. 1994. An experimental investigation of pure coordination games. Amer. Econom. Rev. 84(3) 658-673.

Nelson, R. R. 1982. The role of knowledge in R\&D efficiency. Quart. J. Econom. 97(3) 453470.

Nonaka, I. 1991. The knowledge-creating company. Harvard Bus. Rev. 69(6) 96-104. . 1994. A dynamic theory of organizational knowledge creation. Organ. Sci. 5(1) 14-37.

Polanyi, M. 1966. The Tacit Dimension. Doubleday, New York.

Schelling, T. C. 1960. The Strategy of Conflict. Harvard University Press, Cambridge.

Schober, M. F., H. H. Clark. 1989. Understanding by addressees and overhearers. Cognitive Psych. 21(2) 211-232. 
Shaw, M. E. 1954. Some effects of problem complexity upon problem solution efficiency in different communication nets. J. Experimental Psych. 48(3) 211-217

Singley, M. K., J. R. Anderson. 1989. Transfer of Cognitive Skill. Harvard University Press, Cambridge.

Spender, J. C., R. M. Grant. 1996. Knowledge and the firm. Strategic Management J. 17 5-9.

Thompson, J. D. 1967. Organizations in Action: Social Science Bases of Administrative Theory. McGraw-Hill, New York.

Van Huyck, J., R. Battalio, R. Beil. 1990. Tacit coordination games, strategic uncertainty, and coordination failure. Amer. Econom. Rev. 80(1) 234-248.

von Hippel, E. 1988. The Sources of Innovation. Oxford University Press, New York.

Walsh, J. P., G. R. Ungson. 1991. Organizational memory. Acad. Management Rev. 16(1) 57-91.

Weber, R. A. 2006. Managing growth to achieve efficient coordination in large groups. Amer. Econom. Rev. 96(1) 114-126.

Weber, R. A., C. F. Camerer. 2003. Cultural conflict and merger failure: An experimental approach. Management Sci. 49(4) 400-415.

Weber, R. A., Y. Rottenstreich, C. F. Camerer, M. Knez. 2001. The illusion of leadership: Misattribution of cause in coordination games. Organ. Sci. 12(5) 582-598.

Weick, K. 1969. The Social Psychology of Organizing. Addison-Wesley, Reading.

Wernerfelt, B. 2003. Organizational languages. Working paper, 4278-03, MIT Sloan School of Management, Boston, MA.

Winter, S. 1987. Knowledge and competence as strategic assets. D. J. Teece, ed. The Competitive Challenge: Strategies for Industrial Innovation and Renewal. Ballinger, Cambridge. 
Zander, U., B. Kogut. 1995. Knowledge and the speed of transfer of organizational capabilities: An empirical test. Organ. Sci. 6(1) 76-92. 


\begin{tabular}{l|ccc}
\hline & New pictures & New employee & Total \\
\hline Routine-Intensive & $8(32)$ & $12(60)$ & $20(92)$ \\
Routine-Restricted & $8(32)$ & $12(60)$ & $20(92)$ \\
\hline Total & $16(64)$ & $24(120)$ & $40(184)$ \\
\hline
\end{tabular}

Table 1. Number of sessions (participants) by treatment

\begin{tabular}{|c|c|c|c|c|c|}
\hline \multirow[b]{2}{*}{$\operatorname{Ln}(\text { Period })^{\mathrm{a}}$} & \multirow{2}{*}{$\begin{array}{c}\begin{array}{c}\text { Initial } \\
\text { coordination } \\
\text { (periods } 1-20)\end{array} \\
0.154^{* * *} \\
(0.003)\end{array}$} & \multicolumn{2}{|c|}{$\begin{array}{c}\text { Transfer to } \\
\text { new domain } \\
\text { (periods 21-35) }\end{array}$} & \multicolumn{2}{|c|}{$\begin{array}{c}\text { Transfer to } \\
\text { new employee } \\
\text { (periods 21-35) }\end{array}$} \\
\hline & & $\begin{array}{l}0.071^{* * *} \\
(0.004)\end{array}$ & $\begin{array}{l}0.071^{* * *} \\
(0.004)\end{array}$ & $\begin{array}{l}0.140^{* * *} \\
(0.006)\end{array}$ & $\begin{array}{c}-0.140^{* * *} \\
(0.006)\end{array}$ \\
\hline Routine-Intensive & $\begin{array}{l}0.060^{* * *} \\
(0.018)\end{array}$ & $\begin{array}{l}0.071^{* * *} \\
(0.022)\end{array}$ & $\begin{array}{l}0.060^{* * *} \\
(0.019)\end{array}$ & $\begin{array}{l}-0.030 \\
(0.030)\end{array}$ & $\begin{array}{c}-0.040 \\
(0.027)\end{array}$ \\
\hline Period 20 profit & & & $\begin{array}{c}0.383^{* * *} \\
(0.144)\end{array}$ & & $\begin{array}{l}0.660^{* * *} \\
(0.277)\end{array}$ \\
\hline Constant & $\begin{array}{c}-0.047^{* * *} \\
(0.015) \\
\end{array}$ & $\begin{array}{c}0.267^{* * *} \\
(0.017)\end{array}$ & $\begin{array}{l}0.106^{*} \\
(0.063) \\
\end{array}$ & $\begin{array}{l}0.120^{* * *} \\
(0.024)\end{array}$ & $\begin{array}{c}-0.181 \\
(0.128)\end{array}$ \\
\hline $\mathbf{N}(\mathbf{f i}$ & $800(40)$ & $240(16)$ & $240(16)$ & $360(24)$ & $360(24)$ \\
\hline $\mathbf{R}^{2}$ & 0.653 & 0.507 & 0.581 & 0.474 & 0.517 \\
\hline
\end{tabular}

Standard errors in parentheses

${ }^{\mathrm{a}}$ - For regressions using periods $21-35, \mathrm{Ln}(\mathrm{Period})$ is defined as $\operatorname{Ln}(\operatorname{Period}-20)$

${ }^{*}-\mathrm{p}<0.1 ;{ }^{* *}-\mathrm{p}<0.05 ;{ }^{* * *}-\mathrm{p}<0.01$

Table 2. Random-effects (firm) regressions of firm earnings

\begin{tabular}{l|cccc}
\hline & \multicolumn{2}{|c}{$\begin{array}{c}\text { Average earnings in new } \\
\text { domain (periods 21-24) }\end{array}$} & \multicolumn{2}{c}{$\begin{array}{c}\text { Average earnings by new } \\
\text { employee (periods 21-24) }\end{array}$} \\
\hline Average earnings & 0.391 & 0.156 & -0.108 & -0.007 \\
(periods 1-4) & $(0.229)$ & $(0.226)$ & $(0.290)$ & $(0.291)$ \\
Routine-Intensive & & $0.083^{* *}$ & & -0.045 \\
& & $(0.036)$ & & $(0.031)$ \\
Constant & $0.313^{* * *}$ & $0.295^{* * *}$ & $0.222^{* * *}$ & $0.235^{* * *}$ \\
& $(0.029)$ & $(0.027)$ & $(0.034)$ & $(0.034)$ \\
\hline $\mathbf{N}$ & 16 & 16 & 24 & 24 \\
$\mathbf{R}^{2}$ & 0.173 & 0.408 & 0.006 & 0.097 \\
\hline
\end{tabular}

Standard errors in parentheses

${ }^{*}-\mathrm{p}<0.1 ;{ }^{* *}-\mathrm{p}<0.05 ;{ }^{* * *}-\mathrm{p}<0.01$

Table 3. Firm performance in first four periods following change 


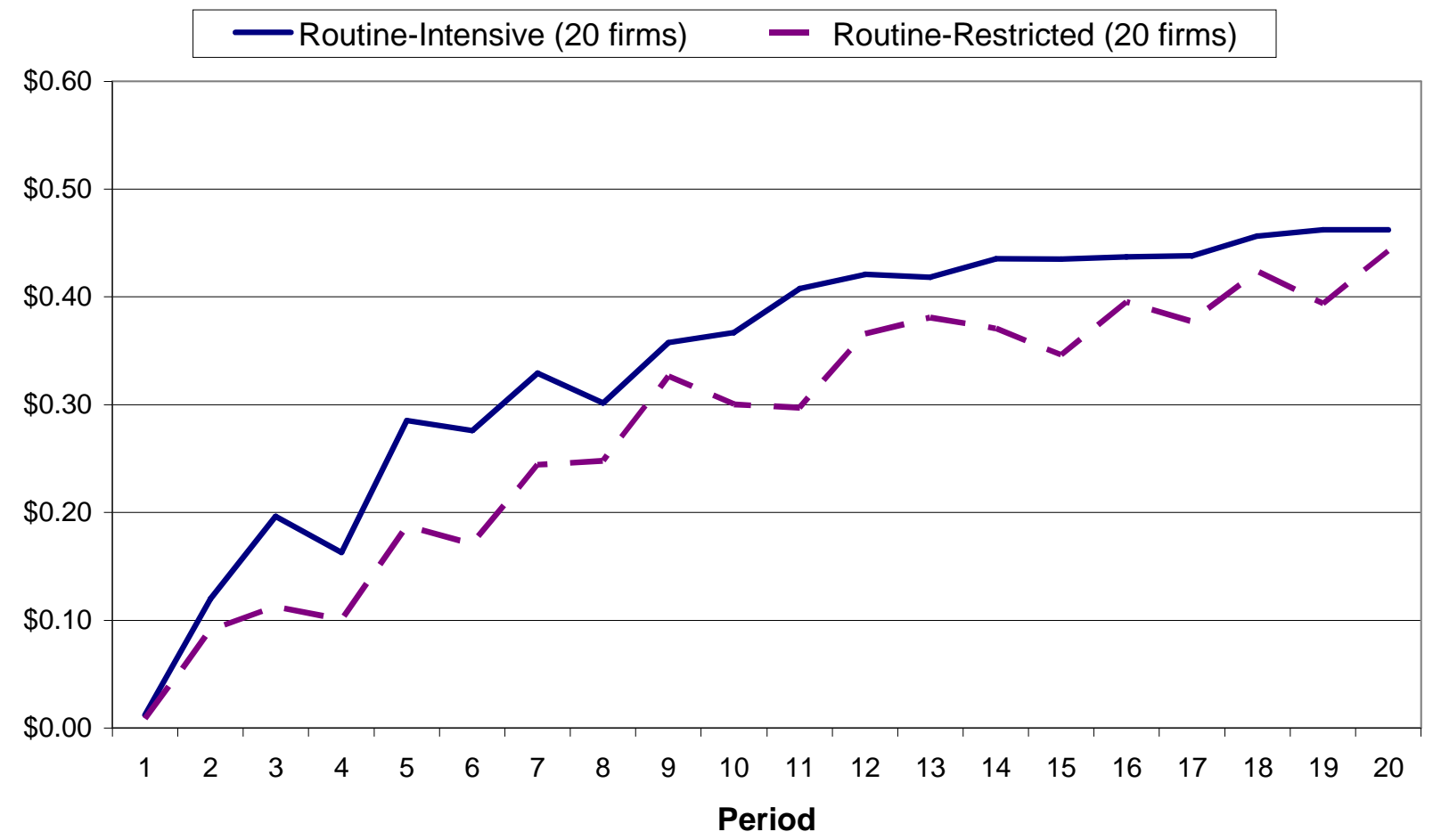

Figure 1. Average firm earnings in periods 1-20 (all firms)

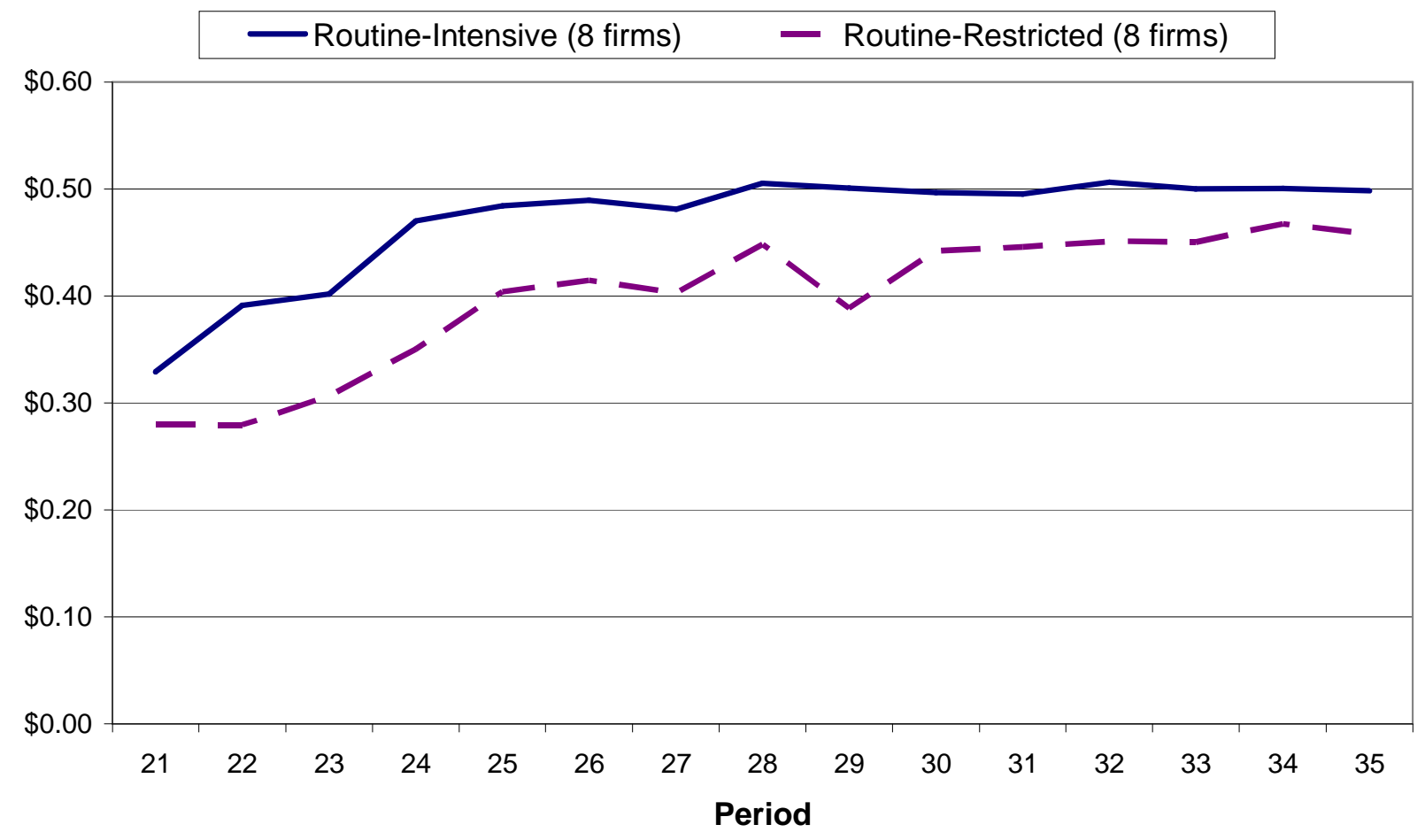

Figure 2. Average firm earnings in periods 21-35 (new domain treatment) 


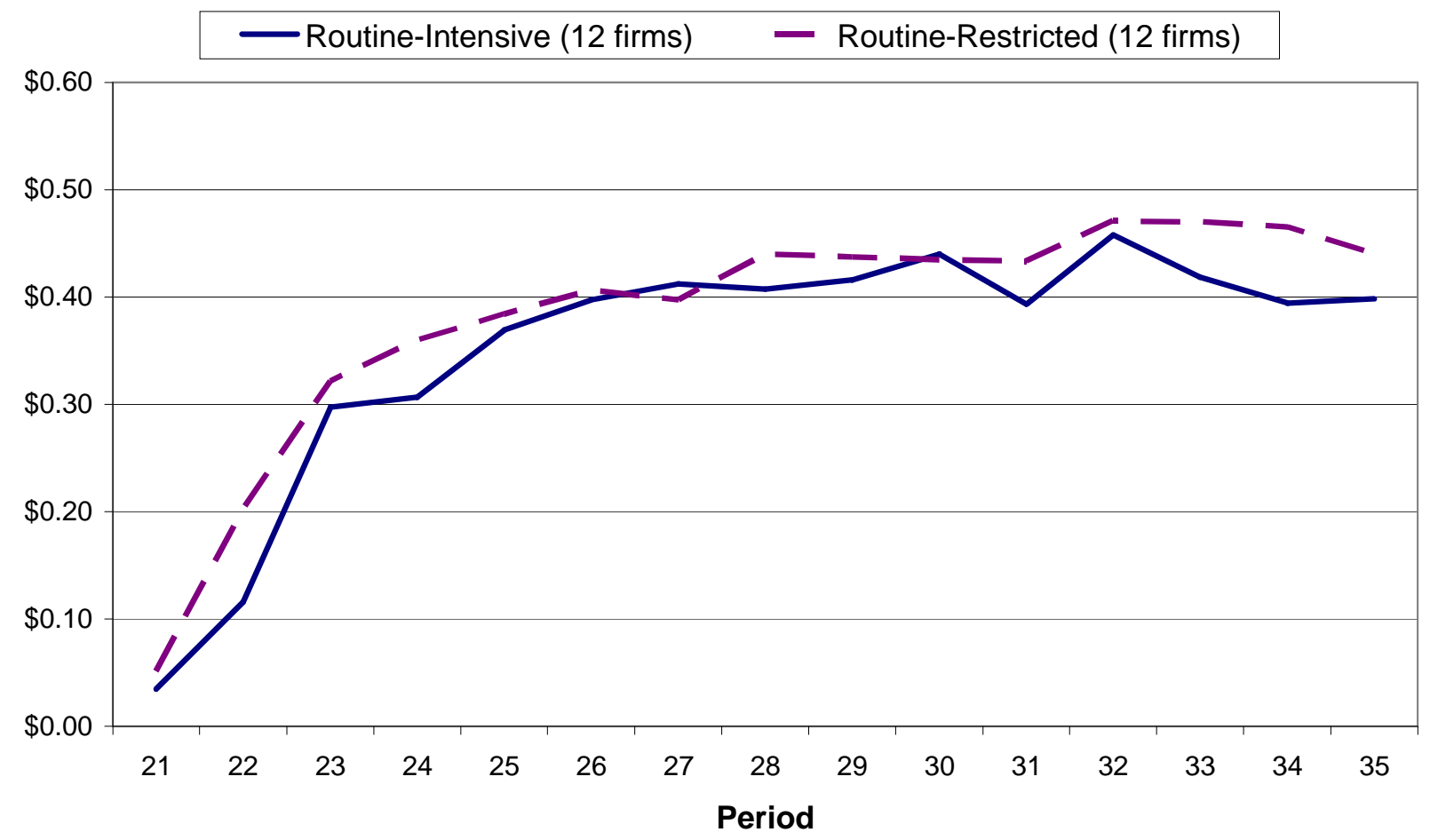

Figure 3. Average new employee earnings in periods 21-35 (new employee treatment) 


\section{Appendix: A model of coordination with explicit agreement and tacit routines}

We present a simple formal model of a firm coordinating activity using tacit routines and explicit agreement. This model - based on the presence of the two mechanisms for solving coordination problems - illustrates how limiting a firm's ability to develop tacit routines will lead to greater reliance on explicit coordination mechanisms (communication and shared explicit knowledge), and the consequences for knowledge transfer to new individuals or related domains.

\section{The model}

Assume that a firm engages in $T$ periods of "production" - where output refers to successful coordination (as in the identification of pictures in our task) - and that the firm's production in any period $t \in\{1, \ldots, T\}$ is determined by a function, $Y\left(R_{t}, E_{t}\right)$, which uses as the two inputs the stock of tacit routines possessed by the firm in period $t\left(R_{t}\right)$ and the amount of explicit shared agreement $\left(E_{t}\right)$. Assume that $Y$ is continuous and twice-differentiable in both arguments throughout. Moreover, assume that $Y$ is increasing in both arguments (i.e., $Y_{1}, Y_{2}>0$ ) and strictly concave in either argument $\left(Y_{11}, Y_{22}<0\right)$. Finally, assume that the marginal productivity of either input is decreasing in the quantity of the other input (i.e., $Y_{12}=Y_{21}<0$ ). ${ }^{23}$

Assume that the stock of explicit agreement in any period $t$ is a function of the amount of explicit agreement in the previous period $\left(E_{t-1}\right)$ and the amount of communication in period $t$ $\left(m_{t}\right)$. Thus, $E_{t}=G\left(E_{t-1}, m_{t}\right)$, where $G$ is increasing in both arguments (i.e., $G_{1}, G_{2}>0$ ), weakly concave in previous shared agreement $\left(G_{11} \leq 0\right)$, and strictly concave in communication $\left(G_{22}<\right.$

\footnotetext{
${ }^{23}$ An example of such a production function is $Y_{t}=\bar{Y}-R_{t}^{-1} E_{t}^{-1}$, where $\bar{Y}$ is a maximum attainable level of productivity. This function corresponds quite closely to the payoff scheme in the experiments here (and in Weber and Camerer 2003) - for instance, with $\bar{Y}=\$ 0.60$. The assumption of diminishing marginal productivity in all cases (i.e., all second derivatives are negative) is reasonable in a setting such as ours, where firm production (of "agreement" or coordination) has an upper bound.
} 
0 ). Since less communication is necessary when there is greater previously established explicit agreement, assume that the impact of period $t$ communication on period $t$ agreement is decreasing in the amount of pre-existing explicit agreement $\left(G_{12}<0\right)$. Assume $E_{0}$ corresponds to some basic body of explicit knowledge jointly held by the population from which firm members are drawn (such as commonly known facts and a common vocabulary). Thus, holding $E_{0}$ constant, greater explicit agreement in any period is obtained by having communicated more in previous periods (having established greater shared explicit knowledge) and by using more communication in the current period.

In any period, the amount of communication $m_{t}$ is determined by the firm's manager (and is the only choice variable for the firm). Communication is costly, as determined by a function $C\left(m_{t}\right)$ that is strictly increasing and weakly convex throughout (i.e., $C_{1}>0, C_{11} \geq 0$ ).

Thus, the firm's profit in period $t$ is given by

$$
\pi\left(R_{t}, E_{t}\right)=Y\left(R_{t}, G\left(E_{t-1}, m_{t}\right)\right)-C\left(m_{t}\right),
$$

and we assume that $\lim _{m_{t} \rightarrow 0} C\left(m_{t}\right)=0$, so that some level of communication $m_{t}>0$ is always optimal.

Finally, we discuss how the stock of tacit routines evolves over time. Assume that such knowledge evolves with experience, but independently of communication. Instead, as organizational scholars have noted (e.g., Gersick and Hackman 1990), tacit routines are likely to develop strongly when groups perform the same task repeatedly with little change in how the task is performed. Therefore, we allow the variable $z$ to refer to the degree of stability in firm operations and, for simplicity, allow $z$ to take on one of two values, with $z=1$ corresponding to (stable) firms with no change in operations across time and $z=0$ to firms that change. We assume that the firm's stock of tacit routines develops according to $R_{t}=R_{0}+F(t, z)$, where $R_{0}$ 
refers to a set of jointly held routines among the population from which firm members are drawn (for instance, tacit norms or rules governing communication).

To capture the effect of experience on the development of tacit routines, we assume that $F$ has the following four properties:

i) $\quad F(1,0)=F(1,1)=0\left(\right.$ the lack of shared experience in period 1 implies $\left.R_{1}=R_{0}\right)$,

ii) $\quad F_{1} \geq 0$ (the stock of tacit routines is weakly increasing over time),

iii) $\quad F_{2}>0$ for all $t>1$ (with any experience, firms with stability in operations always have a greater stock of tacit routines), and

iv) $\quad F_{12} \geq 0$ (the increase in tacit routines over time is always weakly larger in firms with stability in operations).

Firm performance in static environment

In this part of the analysis, we explore only the $T$ periods in which firms perform the same production task repeatedly. In the next section, we explore what happens in period $T+1$, when firms attempt to transfer knowledge and coordination ability to a new domain or employee.

A manager selects the vector of communication across periods $M^{*}=\left\{m_{1}^{*}, \cdots, m_{T}^{*}\right\}$ to maximize profits $\left(\sum_{T} \delta^{t} \pi_{t}\right)$ for any $0<\delta \leq 1$. Then the model produces several predictions regarding firm performance (profits) and firms' use of explicit agreement and communication as a function of firm stability.

The first result simply states that managers in all firms will engage in less communication over time. $^{24}$

Proposition 1: The amount of communication will be strictly decreasing across periods.

\footnotetext{
${ }^{24}$ Proofs are available upon request.
} 
The intuition behind the result is simple: communication is most productive in earlier periods both because it creates knowledge "spillovers" for future periods and because the stock of tacit routines and explicit agreement are lower in earlier periods - while the cost of any given level of communication is constant across periods. Thus, the manager will utilize more communication to coordinate activity in early periods and subsequently, having established a sufficiently large explicit knowledge base, will rely more on this knowledge base and less on communication to ensure coordination in later periods. This holds regardless of whether $z=0$ or $z=1$.

Our second result deals with the key differences between the two kinds of firms.

\section{Proposition 2: In any period, the amount of communication and explicit agreement will be}

lower and the profits will be higher in stable $(z=1)$ firms than in changing ones $(z=0)$.

This result simply states that in the optimal communication sequences $M_{z=1}^{*}$ and $M_{z=0}^{*}$ it must be the case that $m_{t, z=0}^{*}>m_{t, z=1}^{*}$ and $\pi_{t, z=0}^{*}<\pi_{t, z=1}^{*}$ in any period. ${ }^{25}$ The intuition behind this result is straightforward. The stable firms $(\mathrm{z}=1)$ obtain an advantage in their stock of tacit routines (i.e., $R_{t, z=1}>R_{t, z=0}$ for all $t>1$ ) that extends to all periods beyond the first. This makes the productivity of all investments in communication higher for changing firms (even in the first period, because of the "spillovers" to future periods). That is, managers of changing firms have more to gain - in terms of current period profits and future improvements explicit agreement by employing greater communication, while stable firm managers can engage in less communication, and rely less on explicit agreement, due to their natural advantage in tacit

\footnotetext{
${ }^{25}$ If managers are myopic - either in the sense that they maximize profits only in the current period, given $R_{t}$ and $E_{t-1}$ or that they fail to anticipate differences in how $R_{t}$ and $E_{t}$ will evolve - then the result holds only for all periods after the first. That is, myopic managers will engage in the same amount of communication in the first period (because managers in changing firms will not anticipate the greater marginal benefit to their firms of greater "investments" in explicit agreement). In fact, our results suggest most managers are myopic in this sense (the first period communication and profits are almost identical for the two kinds of firms).
} 
routines. Moreover, while changing firms spend more on communication, they never do so to an extent that overcomes the overall advantage held by stable firms (if this were the case, the managers of stable firms would invest in at least this much communication since it is (weakly) cheaper for them to do so). Thus, stable firms will generate higher profits, and will always have lower levels of explicit agreement and communication, than changing ones.

\section{Transferring knowledge}

We now explore what happens when firms undergo change, in which case they have to transfer knowledge - either to a new and closely related domain or to a new individual. We restrict our attention to period $T+1$, or the first period following the change.

In the case of transferring knowledge to a new domain, the firm's profit function in period $T+1$ is identical to the profit function for previous periods:

$$
\pi\left(R_{T+1}, E_{T+1}\right)=Y\left(R_{T+1}, G\left(E_{T}, m_{T+1}\right)\right)-C\left(m_{T+1}\right)
$$

In the case of transferring knowledge to a new employee, we assume that the production and profit functions are the same, representing the "production" of coordination between the manager and the new employee. ${ }^{26}$

The firm manager must then take $R_{T+1}$ and $E_{T}$ as given and choose $m_{T+1}$ to maximize profits in period $T+1$.

Since there is a difference between periods $T$ and $T+1$ - either the change of domains or the introduction of a new employee - it is important to determine what happens to the stocks of tacit routines and explicit agreement as a result of this change. We allow the parameter $0 \leq \beta_{R} \leq$

\footnotetext{
${ }^{26}$ We assume that these production and profit functions also apply to the continuing employees. However, since the stocks of tacit routines and explicit agreement between the manager and continuing employees are unchanged by the introduction of a new employee, we ignore this aspect of the firm production - which is likely to continue as in all periods leading up to $\mathrm{T}$ - and instead focus only on the production of coordination between the manager and the new employee. This is for simplicity.
} 
1 and $0 \leq \beta_{E} \leq 1$ to measure, respectively, the degree to which $R_{T}$ and $E_{T}$ transfer to the new situations. Thus, $\beta_{R}=1$ implies that all of the stock of tacit routines transfers to the new domain, while $\beta_{R}=0$ implies that the entire stock of tacit routines is lost, and similarly for $\beta_{E}=0$ and $\beta_{E}=$ 1 with respect to the stock of explicit agreement.

For the stock of tacit routines in period $T+1$, we then have $R_{T+1}=R_{0}+\beta_{R} F(T+1, z)$, meaning that $\beta_{R}=1$ (full transfer) implies $R_{T+1}=R_{0}+F(T+1, z)$, while $\beta_{R}=0$ (zero transfer) implies $R_{T+1}=R_{0}$. Similarly, for the stock of shared explicit agreement, we have $E_{T+1}=G\left(E_{0}+\beta_{E}\left(E_{T}-E_{0}\right), m_{t}\right)$, where $\beta_{E}=1$ (full transfer) implies $E_{T+1}=G\left(E_{T}, m_{t}\right)$ and $\beta_{E}=0$ (zero transfer) implies $E_{T+1}=G\left(E_{0}, m_{t}\right)$. We can then re-state the profit function for period $T+1$ as:

$$
\pi\left(R_{T+1}, E_{T+1}, \beta_{R}, \beta_{E}\right)=Y\left(R_{0}+\beta_{R} F(T+1, z), G\left(E_{0}+\beta_{E}\left(E_{T}-E_{0}\right), m_{T+1}\right)\right)-C\left(m_{T+1}\right)
$$

Finally, we impose the following assumptions on $\beta_{R}$ and $\beta_{E}$ based on the kind of change experienced by the firm.

In the case of the firm entering a new, closely related domain, the basic features of the production of coordination remain the same, but the previously developed explicit agreement no longer applies. We anticipate that tacit routines will transfer to the new context, due to the high similarity between what the firm does in both cases, but that explicit coordination mechanisms (domain-specific explicit knowledge) will not (Berry and Broadbent 1987, Gersick and Hackman 1990, Cohen and Bacdayan 1994, Darr and Kurtzberg 2000). Thus, in the case of a new domain, we assume that $\beta_{R}>0$ and $\beta_{E}=0$.

In the case of a new employee, we expect transfer will be nearly impossible for tacit routines, which are difficult to transfer to new individuals if not accompanied by explicit communication (Weber 2006). However, explicit agreement, which is more easily 
communicable due to its codifiable nature, will more easily transfer to the new employee (Nanaka 1991, 1994, Grant 1996, Argote and Ingram 2000, Lam 2000). Thus, in the situation involving a new employee, we assume $\beta_{R}=0$ and $\beta_{E}>0$.

The following two results then hold as a direct consequence of the above assumptions and Proposition 2.

Proposition 3a: When firms enter a new domain, profits will be higher in stable $(z=1)$ firms than in changing ones $(z=0)$.

Proposition 3b: When firms incorporate a new employee, profits for this employee will be lower in stable $(z=1)$ firms than in changing ones $(z=0)$.

The intuition behind these two results is straightforward. Entering the period in which the firm undergoes a change $(T+1)$, the stable firms possess a greater stock of tacit routines and the changing firms possess a greater stock of explicit agreement. The assumptions above tell us that each kind of knowledge will transfer to a positive degree in one situation and will not transfer at all in the other case. Therefore, each of the two kinds of firms will have an advantage in dealing with one of the two kinds of change, and a disadvantage in dealing with the other. 